\title{
The usefulness of age and sex to predict all-cause mortality in patients with dilated cardiomyopathy: a single-center cohort study
}

\begin{abstract}
Xiaoping $\mathrm{Li},{ }^{1-3, *} \mathrm{Chi} \mathrm{Cai},{ }^{3, *}$
Rong Luo, ${ }^{4}$ Rongjian Jiang,' Jie

Zeng,' Yijia Tang,' Yang Chen,'

Michael Fu, ${ }^{5}$ Tao He, 'Wei Hua ${ }^{3}$

'Department of Cardiology, Hospital of the University of Electronic Science and Technology of China, Sichuan

Provincial People's Hospital, Chengdu,

Sichuan, ${ }^{2}$ School of Medicine,

University of Electronic Science

and Technology of China, Chengdu,

Sichuan, ${ }^{3}$ Department of Clinical

Electrophysiology, Fuwai Hospital and Cardiovascular Institute, Chinese Academy of Medical Science and Peking Union Medical College, Beijing, ${ }^{4}$ Key Laboratory of Thermoregulation and Inflammation of Sichuan Higher Education Institutes, Chengdu Medical College, Chengdu, Sichuan, People's Republic of China; ${ }^{5}$ Department of Medicine, Sahlgrenska University Hospital/Östra Hospital, Gothenburg, Sweden

*These authors contributed equally to this work
\end{abstract}

Correspondence: Wei Hua

Cardiac Arrhythmia Center, State Key Laboratory of Cardiovascular Disease, Cardiovascular Institute and Fuwai Hospital, National Center for Cardiovascular Diseases, Chinese Academy of Medical Sciences, Peking Union Medical College, 167 Beilishi Road,

Beijing 100037, People's Republic of China

Tel +861088398290

Fax +861068313019

Emaildrhua@aliyun.com

Tao He

Department of Cardiology, Hospital of the University of Electronic Science and Technology of China, Sichuan Provincial People's Hospital, 32 West Second Section First Ring Road, Chengdu, Sichuan 610072,

People's Republic of China

Tel +86 2887394079

$\mathrm{Fax}+862887394013$

Email hch0119@sina.com
This article was published in the following Dove Press journal:

Clinical Interventions in Aging

16 September 2015

Number of times this article has been viewed

Objective: Recent studies have shown that sex and age are associated with outcomes in patients with cardiomyopathy. The purpose of this study was to determine the all-cause mortality of dilated cardiomyopathy (DCM) by age and sex.

Methods and results: The patients were divided into non-elderly (age $<60$ years, $n=811$ ) and elderly (age $\geq 60$ years, $n=331$ ) groups. No difference in the all-cause mortality rate was observed between elderly and non-elderly patients $\left(27.2 \%\right.$ vs $22.2 \%$, log-rank $\left.\chi^{2}=2.604, P=0.107\right)$. Furthermore, no significant difference in mortality was observed between the male and female patients $\left(23.3 \%\right.$ vs $24.5 \%$, log-rank $\left.\chi^{2}=0.707, P=0.400\right)$. However, subgroup analysis revealed that elderly male patients exhibited a higher mortality rate than non-elderly male patients $(29.4 \%$ vs $21.3 \%$, log-rank $\chi^{2}=5.898, P=0.015$ ), while no difference was observed between the elderly female patients and non-elderly female patients. In the Cox analysis, neither age nor sex was a significant independent predictor of all-cause mortality in patients with DCM.

Conclusion: In conclusion, no significant difference in mortality between male and female patients or between the elderly and non-elderly patients was observed. Only among males was a difference in mortality observed; elderly male patients experienced greater mortality than that of non-elderly male patients. No effect of age or sex on all-cause mortality was observed in patients with DCM.

Keywords: elderly, sex, dilated cardiomyopathy, prognosis

\section{Introduction}

Dilated cardiomyopathy (DCM) is a disease of the heart muscle characterized by ventricular dilatation and impaired systolic function; this condition is the third most common cause of heart failure. ${ }^{1,2}$ The prognosis in patients with DCM is poor, with approximately half of all patients dying within 5 years of diagnosis; however, the prediction of death remains a challenge for clinicians. ${ }^{1,2}$

Age and sex are established risk factors of cardiovascular disease and death due to cardiovascular disease. The elderly and males have poor prognoses once heart failure occurs. $^{3-7}$ In a meta-analysis, the Global Group in Chronic Heart Failure reported that the greatest predictor of mortality was age. ${ }^{3}$ The Framingham Heart Study found that the prognosis of women was significantly better than that of men., ${ }^{4,5}$ Similar observations have been reported in patients with advanced heart failure. ${ }^{6,7}$ Furthermore, hormonereplacement therapy appeared to improve survival in postmenopausal women with nonischemic heart failure. ${ }^{8}$

Recently, several studies have suggested that age and sex are also associated with the prognosis of DCM. ${ }^{9-16}$ Older age is reported to predict a poor prognosis, ${ }^{9-11}$ and several previous reports have shown a relationship between male sex and poor 
prognosis, ${ }^{12}$ although the data have been inconsistent, especially for pediatric DCM. ${ }^{12-16}$ In addition, most data on DCM outcomes are from the USA and European countries, and only few studies have investigated the prognosis of this disorder in Asian patients with DCM. Therefore, in the present study, we aimed to evaluate the association of age and sex with all-cause mortality in hospitalized patients with DCM in the People's Republic of China.

\section{Subjects and methods Patients and follow-up}

A retrospective, observational cohort study of DCM patients was conducted from November 2003 to September 2011. The patients were admitted based on the presence of symptoms of decompensate heart failure and physical signs of heart failure, and DCM was defined as systolic dysfunction (left ventricular ejection fraction $[\mathrm{LVEF}] \leq 50 \%$ ) with left ventricular (LV) dilation in the absence of an apparent secondary cause of cardiomyopathy. ${ }^{17}$ Of the 1,317 enrolled patients, 175 patients were excluded from the study because they presented various forms of secondary cardiomyopathy (Figure 1). Thus, 1,142 patients were included in the final analysis. The endpoint of the study was the all-cause mortality, which was assessed for all patients using medical records and medical follow-up calls. Survival data were obtained for all study participants from hospitalization to death. Data from patients who underwent cardiac transplantation were no longer collected after transplantation. If a patient was alive at

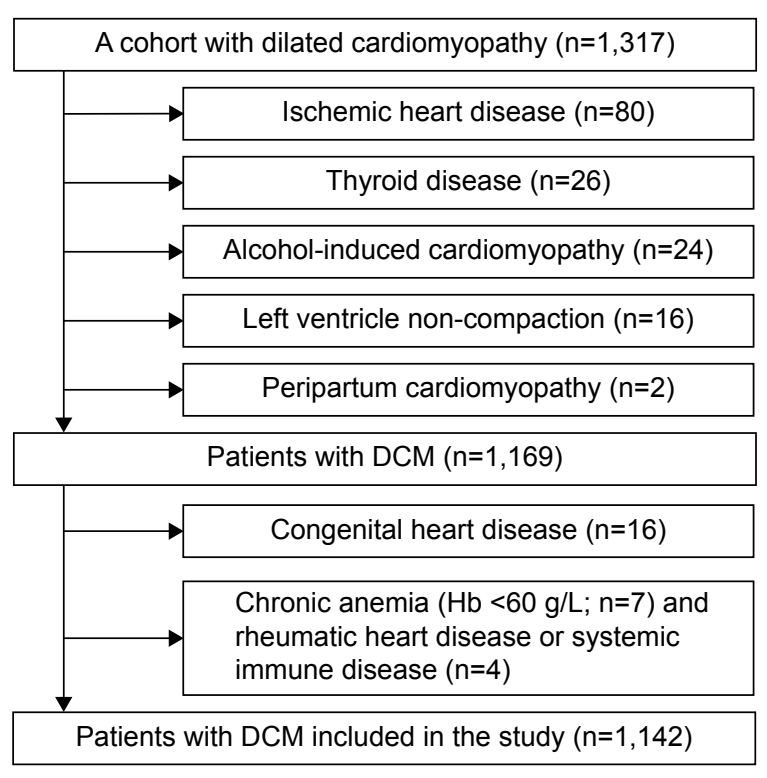

Figure I Flowchart for participants in the present study. Abbreviations: DCM, dilated cardiomyopathy; Hb, hemoglobin. the end of the study, then the date of the most recent clinical

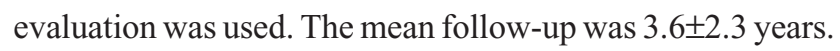
The study was approved by the Ethics Commission of Fuwai Hospital.

\section{Echocardiography}

Patients underwent imaging in the left lateral decubitus position using a commercially available system equipped with a $3.5 \mathrm{MHz}$ transducer. Two-dimensional gray-scale, pulsed, continuous, and color Doppler data were acquired in parasternal and apical views. For tissue Doppler imaging, the sector width was adjusted to obtain a frame rate of at least 115 frames/second. The LVEF was calculated using the biplane Simpson's technique. ${ }^{18}$

\section{Statistical analysis}

Continuous variables are expressed as the mean \pm SD or as medians and interquartile ranges. Comparisons of categorical variables among groups were made using chi-square tests. All tests were two-sided, and a value of $P<0.05$ was considered as statistically significant. Hazard ratios with $95 \%$ confidence intervals were used to estimate the adjusted relative risks for various groups. Kaplan-Meier survival curves were compared using the log-rank test. Multivariate Cox proportional hazards regression models were used to adjust for any confounding variables among groups. The analyses were conducted using SPSS (Statistical Package for the Social Sciences version 16.0, SPSS Inc, Chicago, IL, USA).

\section{Results}

\section{Characteristics of the study population}

Among the 1,142 patients, Han nationality people were 1,098 (96.1\%) while minor nationality people were 44 (3.9\%), patients lived in the North of Yangzi River were 991 $(86.8 \%)$, and patients lived in the Southern of Yazi River were $151(13.2 \%)$. Compared with the non-elderly patients (age $<60$ years, $n=811$ ), the elderly patients (age $\geq 60$ years, $\mathrm{n}=331$ ) were more likely to have atrial fibrillation or a stroke, had longer disease durations, higher systolic blood pressure (SBP), fasting blood glucose levels, N-terminal pro-brain natriuretic peptide (NT-pro-BNP) levels, longer QRS durations, etc (Table 1). The prevalence of DCM was higher in male patients $(n=836)$ than female patients $(n=306)$. Compared with the female patients, the male patients were more likely to have a history of atrial fibrillation or diabetes, more likely to have shorter disease duration, higher diastolic blood pressure, larger left atria, and lower fasting blood glucose levels, etc (Table 1). 


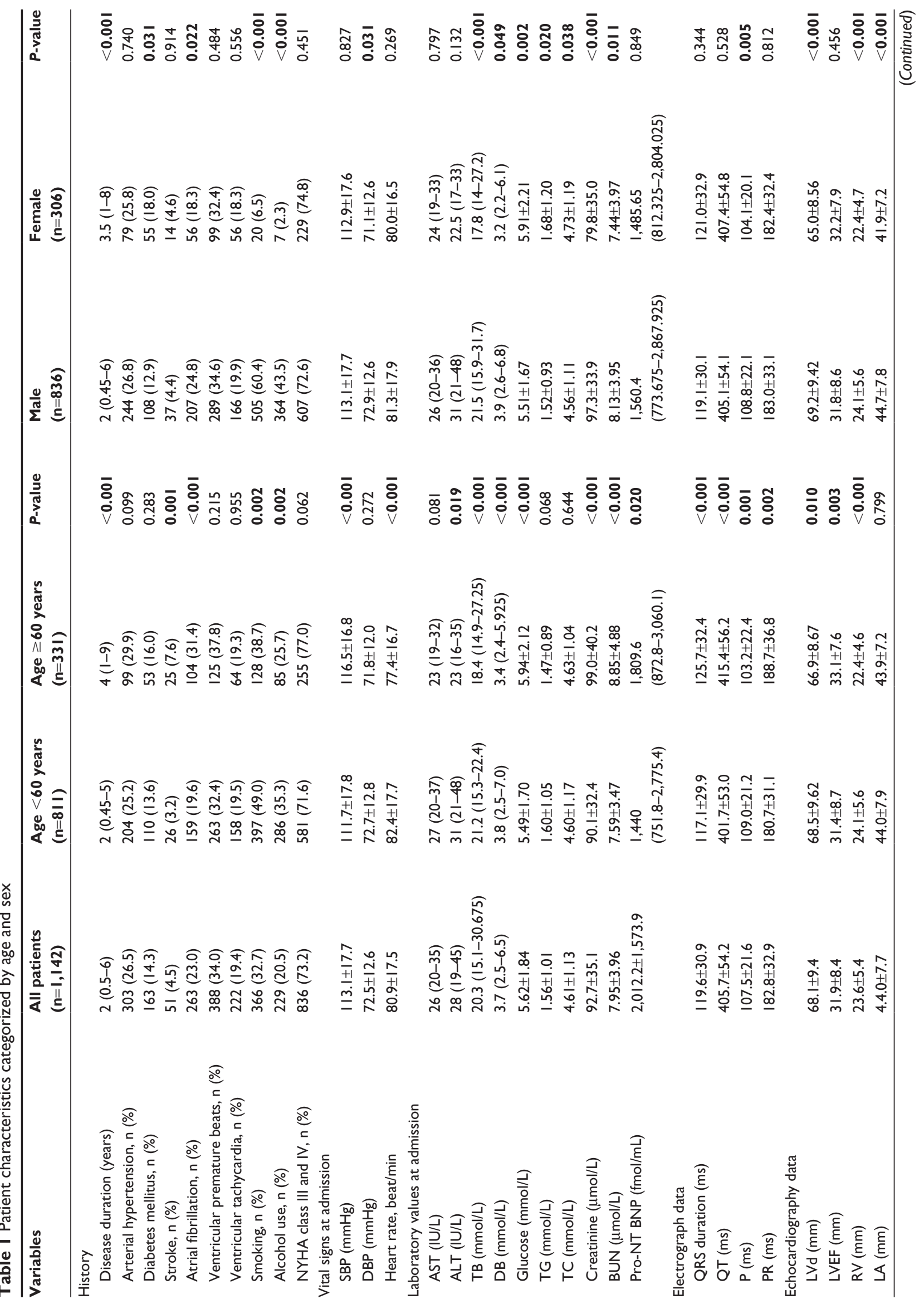




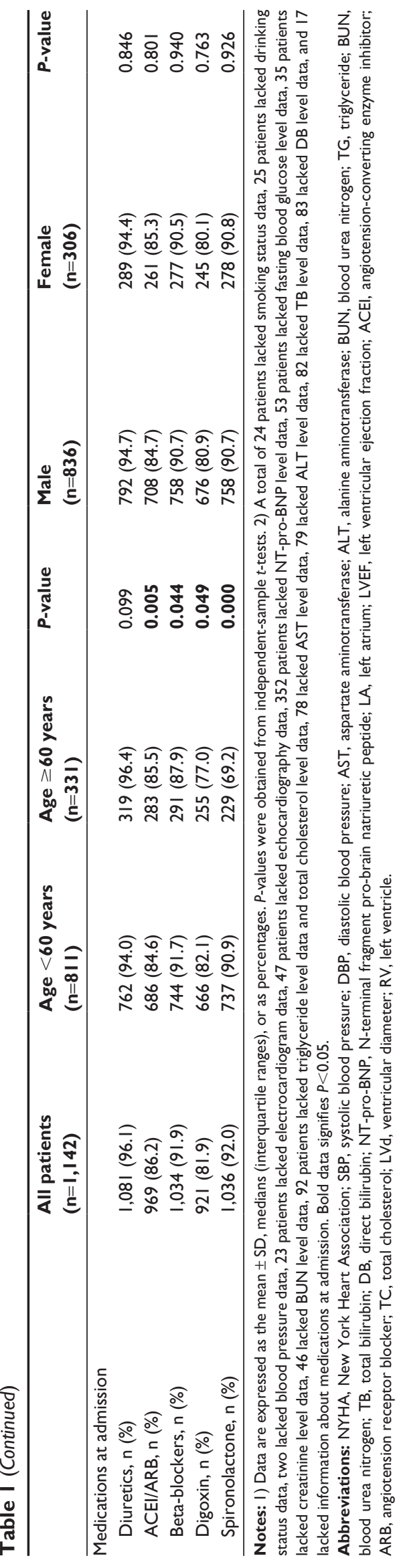

\section{Relationships between age, sex, and all-cause mortality}

Among the 1,142 patients, 270 (23.6\%) died and three $(0.26 \%)$ underwent heart transplantation during a mean follow-up period of $3.6 \pm 2.3$ years. There was trend toward higher all-cause mortality in the elderly compared with non-elderly patients; however, this did not reach statistical significance $\left(27.2 \%\right.$ vs $22.2 \%$, log-rank $\left.\chi^{2}=2.604, P=0.107\right)$. Overall, there was no significant difference between mortality in the male and female patients with $\operatorname{DCM}(23.3 \%$ vs $24.5 \%$, log-rank $\chi^{2}=0.707, P=0.400$; Figure 2).

To determine whether sex confers different degrees of mortality risk in elderly patients with DCM, the whole cohort was split into two subgroups. Among the male patients, a significantly different mortality was found in the elderly patients $(\mathrm{n}=211)$ compared with the non-elderly patients $\left(\mathrm{n}=625,29.4 \%\right.$ vs $21.3 \%$, log-rank $\left.\chi^{2}=5.898, P=0.015\right)$, while no corresponding difference was found between female elderly patients $(\mathrm{n}=120)$ and female non-elderly patients $\left(\mathrm{n}=186,23.3 \%\right.$ vs $25.3 \%$, log-rank $\chi^{2}=1.062$, $P=0.303$; Figure 3 ).

On the other hand, to clarify whether age confers different degrees of mortality risk in different sex patients with DCM, the whole cohort was split into two subgroups. Among the non-elderly patients, no significantly different mortality was found in the male patients $(\mathrm{n}=625)$ compared with the female patients ( $\mathrm{n}=186,21.3 \%$ vs $25.3 \%, \log$-rank $\chi^{2}=3.072, P=0.080$ ). Similarly, no corresponding difference was found between the elderly male $(\mathrm{n}=211)$ and female patients $\left(\mathrm{n}=120,29.4 \%\right.$ vs $23.3 \%$, log-rank $\chi^{2}=1.725$, $P=0.189$; Figure 4).

\section{Cox proportional hazard models}

Univariate analysis of the clinical, laboratory, electrographic, and electrocardiographic data revealed that ventricular premature beats, disease course, New York Heart Association (NYHA) functional class, SBP, QRS duration, LV diameter, LVEF, right ventricular diameter, left atrial diameter, NT-proBNP levels, creatinine levels, and fasting blood glucose levels were significant predictors of all-cause mortality in patients with DCM. Neither age nor sex was entered into the Cox multivariate analysis. After adjusting for age, sex, tobacco smoking, alcohol use, right ventricular diameter, and LVEF, Cox multivariate analysis showed that ventricular premature beats, SBP, QRS duration, left atrium diameter, and fasting blood glucose levels were the strongest independent predictors of all-cause mortality in patients with DCM. Neither age nor sex was a predictor of all-cause mortality in the present study (Table 2). 

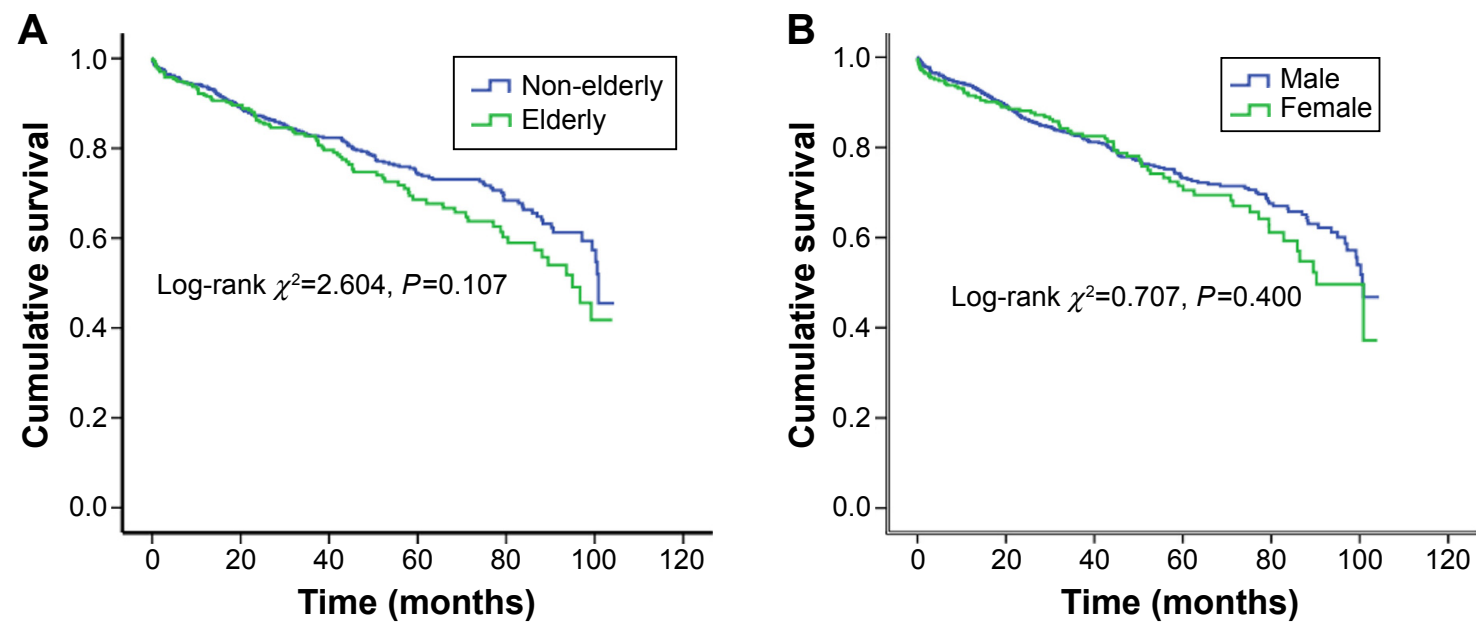

Figure 2 Kaplan-Meier survival curves for the elderly (age $\geq 60$ years) and non-elderly patients (age $<60$ years) with dilated cardiomyopathy (DCM).

Notes: (A) shows the survival curves for the elderly and non-elderly DCM patients (log-rank $\left.\chi^{2}=2.604, P=0.107\right)$. (B) shows the survival curves for the male and female patients with DCM (log-rank $\left.\chi^{2}=0.707, P=0.400\right)$.

\section{Discussion}

In this study, we investigated the associations between age, sex, and all-cause mortality in patients with DCM. Our findings suggest that age and sex offered predictive value for all-cause mortality only in the male subgroup of DCM patients; the elderly male patients exhibited significantly higher all-cause mortality than that of the non-elderly male patients. However, neither age nor sex was independent predictors of all-cause mortality in patients with DCM.

The present data confirm that DCM was less common in women than in men, as has been shown previously. ${ }^{19-21}$ In the present study, men were cigarette smokers more frequently than women. Renal failure, an important prognostic factor in heart failure, was also more common in men; however, women had diabetes more often than men. These findings are in agreement with recent data. ${ }^{20,21}$

In the present study, although no difference in all-cause mortality was observed between the male and female patients or between the elderly and non-elderly patients, elderly male patients exhibited higher mortality rates than those of non-elderly male patients. Griffin et al first partitioned the data by age at diagnosis in children and suggested a
A

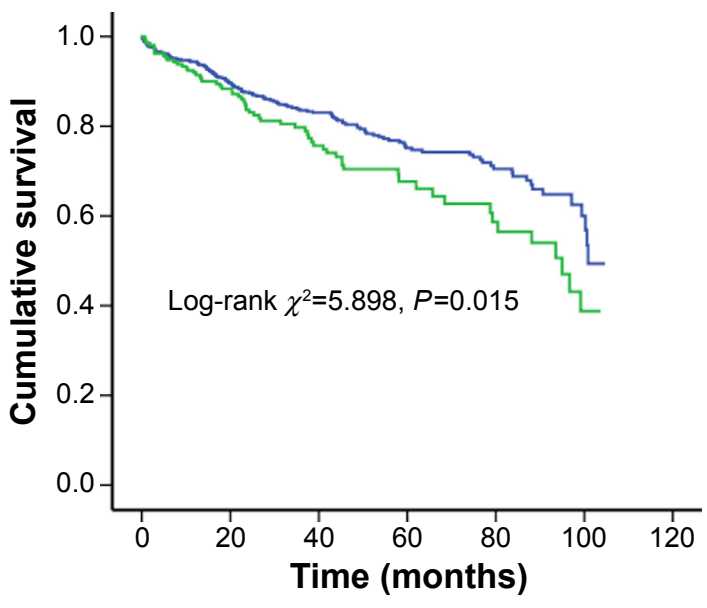

B

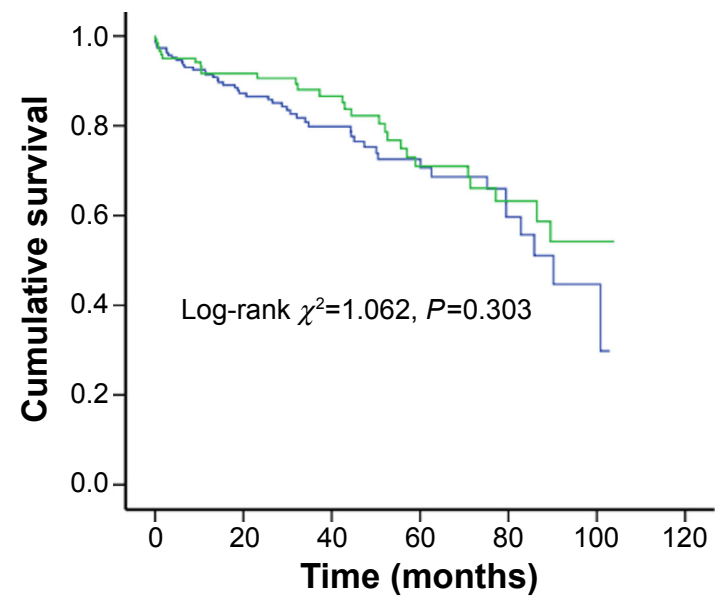

\section{$\neg$ Non-elderly $\neg$ Elderly}

Figure 3 Kaplan-Meier survival curves for the elderly and non-elderly patients with DCM, stratified by sex $\left([\mathbf{A}]\right.$ : log-rank $\chi^{2}=5.898, P=0.015$ in male; $[\mathbf{B}]$ : log-rank $\chi^{2}=1.062$, $P=0.303$ in female).

Abbreviation: DCM, dilated cardiomyopathy. 
A

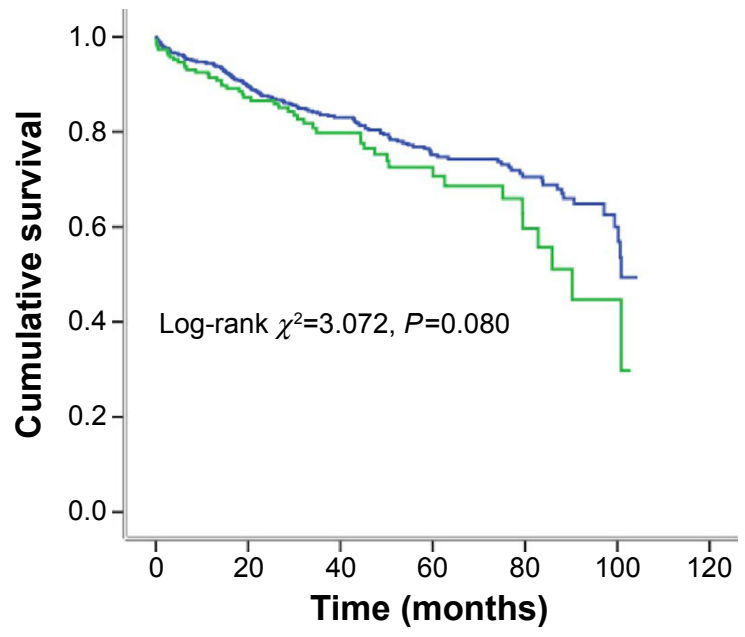

B

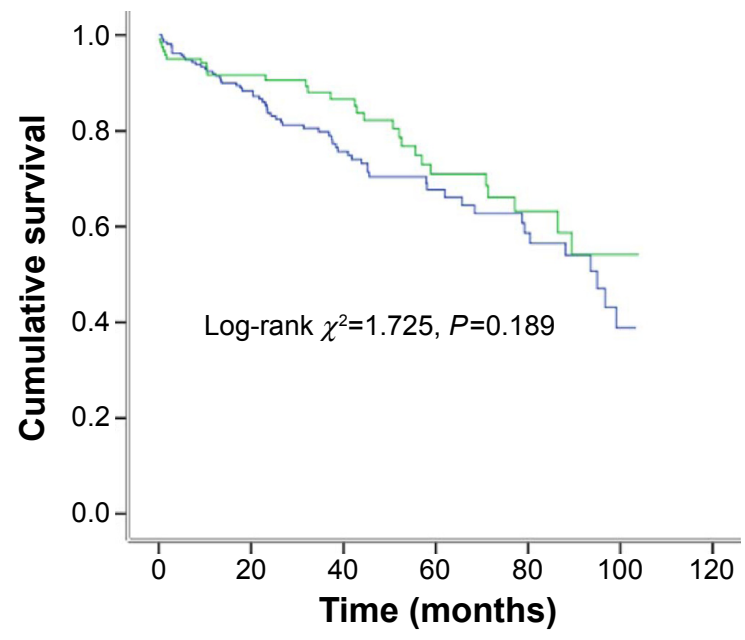

\section{$\neg$ Male $\square$ Female}

Figure 4 Kaplan-Meier survival curves for the male and female patients with $D C M$, stratified by age ([A]: log-rank $\chi^{2}=3.072, P=0.080$ in non-elderly; $[\mathbf{B}]$ : log-rank $\chi^{2}=2.725$, $P=0.189$ in elderly).

Abbreviation: DCM, dilated cardiomyopathy.

relationship between age and outcome; older children had worse outcomes. ${ }^{13}$ In Australia, a national population-based study of DCM found that age was one of the risk factors for mortality in DCM. ${ }^{14}$ Similarly, a New Zealand study also found a difference in survival rates across ages. ${ }^{10}$ However, despite their other positive findings, Chen et al did not find an age-related difference in mortality. ${ }^{15}$ Likewise, Venugopalan et al did not find an age difference when comparing mortality or disease progression with recovery. ${ }^{16}$ In a nationwide study of DCM in Japan, it was found that both male sex and higher age were among the five strongest predictors of mortality. ${ }^{10}$

There was no standard criterion for elderly as various countries and societies consider the different onset of elderly age. Most developed Western countries set the age of 65 years for elderly, while the United Nations and developing countries have agreed that 60 years may be usually

Table 2 Cox regression of all-cause mortality in patients with DCM

\begin{tabular}{|c|c|c|c|c|c|c|}
\hline \multirow[t]{2}{*}{ Variable } & \multicolumn{3}{|c|}{ Univariate analysis } & \multicolumn{3}{|c|}{ Multivariate analysis } \\
\hline & HR & $95 \% \mathrm{Cl}$ & $P$-value & HR & $95 \% \mathrm{Cl}$ & $P$-value \\
\hline Age & 1.007 & $0.998-1.017$ & 0.135 & 1.004 & $0.991-1.016$ & 0.551 \\
\hline Sex & 1.203 & $0.892-1.624$ & 0.226 & 1.293 & $0.887-\mid .887$ & 0.182 \\
\hline Ventricular premature beat & $\mathrm{I} .447$ & I.137-I.842 & 0.003 & 1.354 & $1.017-1.802$ & 0.038 \\
\hline NYHA functional class & 1.588 & $1.352-1.866$ & $<\mathbf{0 . 0 0 I}$ & 1.223 & $0.990-1.511$ & 0.062 \\
\hline Disease duration & 1.027 & $1.010-1.044$ & 0.001 & 1.012 & $0.990-1.035$ & 0.291 \\
\hline Smoker & 0.971 & $0.848-1.110$ & 0.663 & 0.982 & $0.812-1.187$ & 0.853 \\
\hline Drinker & 0.891 & $0.765-1.039$ & 0.140 & 0.947 & $0.768-1.168$ & 0.612 \\
\hline Systolic blood pressure & 0.982 & $0.975-0.989$ & $<0.001$ & 0.984 & $0.975-0.994$ & 0.001 \\
\hline QRS duration & 1.009 & $1.006-1.013$ & $<0.001$ & 1.010 & $1.005-1.014$ & $<0.001$ \\
\hline Left ventricle & 1.037 & $1.024-1.050$ & $<0.001$ & 1.003 & $0.983-1.022$ & 0.789 \\
\hline Right ventricle & 1.063 & I.039-1.087 & $<\mathbf{0 . 0 0 1}$ & 1.015 & $0.985-1.045$ & 0.329 \\
\hline Left atrium & 1.055 & $1.040-1.070$ & $<0.00$ I & 1.047 & $1.025-1.069$ & $<0.001$ \\
\hline LVEF & 0.964 & $0.950-0.979$ & $<\mathbf{0 . 0 0 I}$ & 0.980 & $0.960-1.001$ & 0.057 \\
\hline NT-pro-BNP & 5.665 & $3.587-8.945$ & $<0.001$ & & & \\
\hline FBG & 1.098 & $1.043-1.156$ & $<\mathbf{0 . 0 0 1}$ & 1.098 & I.027-I.I74 & 0.006 \\
\hline Creatinine & 1.004 & $1.002-1.007$ & 0.001 & 1.003 & $1.000-1.006$ & 0.053 \\
\hline
\end{tabular}

Notes: The variables analyzed in the multivariate Cox mode included age, sex, ventricular premature beat, drinking and smoke status, disease duration, NYHA functional classes, systolic blood pressure, QRS duration, left ventricular, right ventricle, left atrium diameter, LVEF, FBG, and creatinine. Bold data signifies $P<0.05$.

Abbreviations: DCM, dilated cardiomyopathy; NYHA, New York Heart Association; LVEF, left ventricular ejection fraction; NT-pro-BNP, N-terminal fragment pro-brain natriuretic peptide; FBG, fasting blood glucose; $\mathrm{Cl}$, confidence interval; $\mathrm{HR}$, Hazard ratio. 
denoted as old age. ${ }^{22-24}$ As a developing country and according to the standard of Chinese Geriatrics Society on elderly, cutoff for elderly was 60 years in the present study. ${ }^{25}$ The main outcomes did not change even if we took the cutoff for elderly as 65 years in the Kaplan-Meier survival and Cox analyses; there was still no difference between the non-elderly and elderly patients $(22.4 \%$ vs $29 \%$, log-rank $\chi^{2}=3.247, P=0.072$ ).

Sex differences in the cardiovascular system have largely been attributed to the effects of sex steroid hormones, such as estrogen and testosterone. The effects of estrogen on the cardiovascular system include rapid vasodilatation, reduced vessel-wall responses to injury, reduced development of atherosclerosis, and the prevention of apoptosis in cardiac myocytes during heart failure. ${ }^{26-28}$ Testosterone inversely influences myocardial remodeling after myocardial infarction and activates nuclear factor- $\kappa \mathrm{B}$, which contributes to inflammatory mechanisms. ${ }^{29-31}$

In the murine model of DCM, the 6-month survival rate was significantly better in females than in males, and basal and isoproterenol-stimulated fractional shortening were preserved in female transgenic mice. ${ }^{32}$ In male and female spontaneously hypertensive rats, aged male rats showed a significant reduction in the peak stroke volume index and an increase in the end-diastolic volume index compared with age-matched control rats. ${ }^{33}$ Echeverria et al found that LV function is better preserved in women than in men presenting with congestive heart failure. ${ }^{34} \mathrm{~A}$ study by Olivetti et al of autopsy tissue from patients free of cardiovascular disease found that aging is associated with cardiac myocyte cell loss and reactive hypertrophy in men but not in women. ${ }^{35}$ Their findings suggest that the myocardium of men, especially elderly men, may be more vulnerable to the effects of cardiac damage compared with that of elderly women.

The present study has several limitations. Like all hospital-based cohorts, this study sample was drawn from a selected population of patients who had been referred for treatment. Because the NT-pro-BNP test was not commonly used until the later years of this study and NT-pro-BNP test data were missing for 352 patients, we excluded this data from the multivariate Cox analysis to avoid a potential confound in the statistical analyses. A total of $14.4 \%$ patients $(n=165)$ were lost to follow-up because of circumstances beyond our control, such as the lack of communication in rural areas, and the main outcomes did not change if we removed these individuals who were lost to follow-up from the Kaplan-Meier survival and Cox analyses. Ideally, all patients with DCM should be shown to be free of coronary artery disease. In practice, however, coronary arteriography is not routinely performed in all patients with congestive heart failure. Because retrospective studies cannot control the conditions under which patients are recruited or investigated, it follows that most retrospective studies of DCM have to compromise on the completeness of data on coronary artery disease in their subjects. In an Icelandic study, three-fourths of the patients were shown to have normal coronary arteries; ${ }^{36}$ however, no coronary imaging results were obtained in a UK questionnaire-based study. ${ }^{37}$ A previous retrospective study, based on the entire Mayo Clinic practice, including referral patients, found angiographic evidence of normal coronary arteries in $58 \%$ of DCM patients. ${ }^{9}$

A very small subgroup with ischemic heart disease was observed in the present study compared with the expected proportion. Moreover, aside from those patients who had previously undergone coronary artery angiography, coronary computerized tomography (CT) scan, or cardiac radionuclide imaging in other hospitals, only 334 patients underwent coronary artery angiography in the present study and only 80 of these patients were found to have coronary artery disease at our hospital.

Despite these limitations in the present study on patients with DCM, we conclude that there was no significant difference in mortality between the male and female patients or between the elderly and non-elderly patients. Elderly male patients experienced greater mortality than non-elderly male patients. Neither age nor sex played an important role in allcause mortality in patients with DCM.

\section{Acknowledgment}

This study was supported by grants from the National Natural Science Foundation of China (Nos 81000104, 81160141, and 81470521).

\section{Author contributions}

All authors contributed toward data analysis, drafting and revising the paper and agree to be accountable for all aspects of the work.

\section{Disclosure}

The authors report no conflicts of interest in this work.

\section{References}

1. Richardson P, McKenna W, Bristow M, et al. Report of the 1995 World Health Organization/International Society and Federation of Cardiology Task Force on the Definition and Classification of Cardiomyopathies. Circulation. 1996;93(5):841-842.

2. Katz AM. Cardiomyopathy of overload. A major determinant of prognosis in congestive heart failure. $N$ Engl J Med. 1990;322(2):100-110. 
3. Pocock SJ, Ariti CA, McMurray JJ, et al. Meta-analysis global group in chronic heart failure. Eur Heart J. 2013;34(19):1404-1413.

4. Ho KK, Anderson KM, Kannel WB, Grossman W, Levy D. Survival after the onset of congestive heart failure in Framingham Heart Study subjects. Circulation. 1993;88(1):107-115.

5. McKee PA, Castelli WP, McNamara PM, Kannel WB. The natural history of congestive heart failure: the Framingham study. $N$ Engl $J$ Med. 1971;285(26):1441-1446.

6. Adams KF Jr, Dunlap SH, Sueta CA, et al. Relation between gender, etiology and survival in patients with symptomatic heart failure. $J \mathrm{Am}$ Coll Cardiol. 1996;28(7):1781-1788.

7. Adams KF Jr, Sueta CA, Gheorghiade M, et al. Gender differences in survival in advanced heart failure. Insights from the FIRST study. Circulation. 1999;99(14):1816-1821.

8. Reis SE. Postmenopausal estrogen use predicts improved survival in women with congestive heart failure. Circulation. 1998;98:I205. (Abstract).

9. Fuster V, Gersh BJ, Guiliani ER, Tajik AJ, Brandenburg RO, Frye RL. The natural history of idiopathic dilated cardiomyopathy. Am J Cardiol. 1981;47(3):525-531.

10. Ikram H, Williamson HG, Won M, Crozier IG, Wells EJ. The course of idiopathic dilated cardiomyopathy in New Zealand. Br Heart $J$. 1987;57(6):521-527.

11. Sugrue DD, Rodeheffer RJ, Codd MB, Ballard DJ, Fuster V, Gersh BJ. The clinical course of idiopathic dilated cardiomyopathy: a populationbased study. Ann Intern Med. 1992;117(2):117-123.

12. Katsuyuki Miura, Akira Matsumori, Ali Nasermoaddeli, et al. Prognosis and prognostic factors in patients with idiopathic dilated cardiomyopathy in Japan results from a nationwide study. Circ J. 2008;72(3): 343-348.

13. Griffin ML, Hernandez A, Martin TC, et al. Dilated cardiomyopathy in infants and children. J Am Coll Cardiol. 1988;11(1):139-144.

14. Daubeney PE, Nugent AW, Chondros P, et al. Clinical features and outcomes of childhood dilated cardiomyopathy: results from a national population-based study. Circulation. 2006;114(24):2671-2678.

15. Chen SC, Nouri S, Balfour I, Jureidini S, Appleton RS. Clinical profile of congestive cardiomyopathy in children. $J$ Am Coll Cardiol. 1990;15(1):189-193.

16. Venugopalan $\mathrm{P}$, Houston AB, Agarwal AK. The outcome of idiopathic dilated cardiomyopathy and myocarditis in children from the west of Scotland. Int J Cardiol. 2001;78(2):135-141.

17. Report of the WHO/ISFC task force on the definition and classification of cardiomyopathies. Br Heart J. 1980;44(6):672-673.

18. Lang RM, Bierig M, Devereux RB, et al. Recommendations for chamber quantification: a report from the American Society of Echocardiography's Guidelines and Standards Committee and the Chamber Quantification Writing Group, developed in conjunction with the European Association of Echocardiography, a branch of the European Society of Cardiology. J Am Soc Echocardiogr. 2005;18(12):1440-1463.

19. Gustafsson F, Torp-Pedersen C, Burchardt H, et al. Female sex is associated with a better long-term survival in patients hospitalized with congestive heart failure. Eur Heart J. 2004;25(2):129-135.
20. Galvao M, Kalman J, DeMarco T, et al. Gender differences in inhospital management and outcomes in patients with decompensated heart failure: analysis from the Acute Decompensated Heart Failure National Registry (ADHERE). J Card Fail. 2006;12(2):100-107.

21. Opasich C, De Feo S, Ambrosio GA, et al. The 'real' woman with heart failure. Impact of sex on current in-hospital management of heart failure by cardiologists and internists. Eur J Heart Fail. 2004;6(6):769-779.

22. Binstock RH. Changing criteria in old-age programs: the introduction of economic status and need for services. Gerontologist. 1994;34(6): 726-730.

23. United Nations Department of Economic and Social Affairs. The Aging of Population and Its Economic and Social Implications. Population Studies. No 26. New York: United Nations Department of Economic and Social Affairs; 1956:7.

24. Sorrell JM. As good as it gets? Rethinking old age. J Psychosoc Nurs Ment Health Serv. 2008;46(5):21-24.

25. Chinese Geriatrics Society, Editorial Board of Chinese Journal of Geriatrics. Standard on Chinese healthy elderly. Chin J Geriatr. 2013;32:801.

26. Mendelsohn ME, Karas RH. The protective effects of estrogen on the cardiovascular system. $N$ Engl J Med. 1999;340(23):1801-1811.

27. Simoncini T, Genazzani AR, Liao JK. Nongenomic mechanisms of endothelial nitric oxide synthase activation by the selective estrogen receptor modulator raloxifene. Circulation. 2002;105(11):1368-1373.

28. Kim JK, Pedram A, Razandi M, et al. Estrogen prevents cardiomyocyte apoptosis through inhibition of reactive oxygen species and differential regulation of p38 kinase isoforms. J Biol Chem. 2006;281(10):6760-6767.

29. Baltatu O, Cayla C, Iliescu R, et al. Abolition of end-organ damage by antiandrogen treatment in female hypertensive transgenic rats. Hypertension. 2003;41(3 Pt 2):830-833.

30. Cavasin MA, Tao ZY, Yu AL, et al. Testosterone enhances early cardiac remodeling after myocardial infarction, causing rupture and degrading cardiac function. Am J Physiol Heart Circ Physiol. 2006;290(5): H2043-H2050.

31. Planavila A, Laguna JC, Vazquez-Carrera M. Nuclear factor-kappaB activation leads to down-regulation of fatty acid oxidation during cardiac hypertrophy. J Biol Chem. 2005;280(17):17464-17471.

32. Kadokami T, McTiernan CF, Kubota T, Frye CS, Feldman AM. Sexrelated survival differences in murine cardiomyopathy are associated with differences in TNF-receptor expression. J Clin Invest. 2000;106(4): 589-597.

33. Pfeffer JM, Pfeffer MA, Fletcher P, Fishbein MC, Braunwald E. Favorable effects of therapy on cardiac performance in spontaneously hypertensive rats. Am J Physiol. 1982;242(5):H776-H784.

34. Echeverria HH, Bilsker MS, Myerburg RJ, Kessler KM. Congestive heart failure: echocardiographic insights. Am J Med. 1983;75(5):750-755.

35. Olivetti G, Giordano G, Corradi D, et al. Sex differences and aging: effects on the human heart. J Am Coll Cardiol. 1995;26(4):1068-1079.

36. Bjarnason I, Jonsson S, Hardarson T. Mode of inheritance of hypertrophic cardiomyopathy in Iceland: Echocardiographic study. Br Heart J. 1982;47(2):122-129.

37. Williams DG, Olsen EGJ. Prevalence of overt dilated cardiomyopathy in two regions of England. Br Heart J. 1985;54(2):153-155.
Clinical Interventions in Aging

\section{Publish your work in this journal}

Clinical Interventions in Aging is an international, peer-reviewed journal focusing on evidence-based reports on the value or lack thereof of treatments intended to prevent or delay the onset of maladaptive correlates of aging in human beings. This journal is indexed on PubMed Central, MedLine,

\section{Dovepress}

CAS, Scopus and the Elsevier Bibliographic databases. The manuscript management system is completely online and includes a very quick and fair peer-review system, which is all easy to use. Visit http://www.dovepress. com/testimonials.php to read real quotes from published authors. 